\title{
Comparison of Hounsfield Unit and Intraoperative "GATA Scale" Score to Determine Requirement of DJ Stent Insertion in Ureteral Stone Treatment
}

\section{Üreter Taşı Tedavisinde DJ Stent Yerleştirme Gerekliliğini Belirlemek Için Hounsfield Ünitesi ve Intraoperatif "GATA Skala" Puanının Karşılaştırılması}

\author{
(D) Caner Ediz1, (D) Serkan Akan1, (D) Suna Ediz Şahin², (D) Muhammed Cihan Temel1, (D) Yunus Emre Kızılkan1, \\ (D) Hasan Hüseyin Tavukçu1, (D) Ömer Yılmaz¹ \\ 1Sultan Abdülhamid Han Training and Research Hospital, Clinic of Urology, Istanbul, Turkiye \\ ${ }^{2}$ Göztepe Training and Research Hospital, Clinic of Radiology, Istanbul, Turkiye
}

\section{What's known on the subject? and What does the study add?}

This work contrary to what is known show that there is a relationship between hounsfield unit and stone size, New scale sets the criteria for DJ stent placement.

\begin{abstract}
Objective: In this study, we aimed to determine the contribution of hounsfield unit (HU) measurement with non-contrast-enhanced computed tomography to the treatment of a single ureteral stone, and compare the value of HU and intraoperative "GATA scale" score in deciding for DJ stent placement in patients with a single ureteral stone.

Materials and Methods: Ninety patients diagnosed with a single ureteral stone in our clinic between January 2018 and September 2018 were evaluated prospectively. We planned a new scale called "GATA scale" with three benchmarks. The validity and reliability of HU were compared with those of GATA scale score. Statistical significance was defined as $p<0.05$.

Results: The mean stone volume at diagnosis was $245.29 \pm 23.9 \mathrm{~mm}^{3}$. The mean HU of ureteral stones was $1065.21 \pm 33.5$. The mean total score according to GATA scale was $6.44 \pm 0.2$. To determine the threshold value for factors affecting stent placement after lithotripsy, receiver operating characteristic analysis was performed for stone volume, laser duration, total energy to complete laser lithotripsy and GATA scale score and showed that the optimal thresholds were $164.01 \mathrm{~mm}^{3}, 4.25 \mathrm{mins}, 1004 \mathrm{~W}$ and 7.5, respectively.

Conclusion: In clinical practice, GATA scale can be used in decision making for DJ stents placement. Stent placement following lithotripsy is recommended especially in patients with a stone volume of greater than $160 \mathrm{~mm}^{3}$ or total energy to complete laser lithotripsy over $1000 \mathrm{~W}$ or laser duration longer than 4 minutes or GATA scale score higher than 7.
\end{abstract}

Keywords: Ureteral stone, Hounsfield unit, Laser lithotripsy

Öz

Amaç: Bu çalışmada, kontrastsız bilgisayarlı tomografi ile hounsfield ünitesi (HÜ) ölçümünün üreter taşı tedavisine katkısını belirlemeyi ve DJ yerleştirilmesi gereksinimini belirlemek için HÜ ve intraoperatif "GATA skala" puanlarının karşılaştırılmasını amaçladık.

Gereç ve Yöntem: Ocak 2018 ve Eylül 2018 tarihleri arasında kliniğimizde tek bir üreter taşı tanısı konan 90 hasta prospektif olarak değerlendirildi. Üç kriter ile "GATA ölçeği" adı verilen yeni bir ölçek planladık. HÜ'nün geçerliliği ve güvenilirliği için GATA skala skoru ile karşılaştırıldı. İstatistiksel anlamlılık $p<0,05$ olarak tanımlandı.

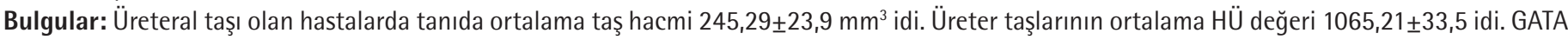
ölçeğine göre ortalama toplam puan $6,44 \pm 0,2$ idi. Litotripsi sonrası stent yerleşimini etkileyen faktörlerin eşik değerlerini belirlemek için taş hacmi,

Correspondence: Caner Ediz MD, Sultan Abdülhamid Han Training and Research Hospital, Clinic of Urology, İstanbul, Turkiye

Phone: +90 5335805080 E-mail: drcanerediz@gmail.com ORCID-ID: orcid.org/0000-0001-9717-1209

Received: 08.07.2019

Accepted: 08.10.2019

Cite this article as: Ediz C, Akan S, Ediz Şahin S, Temel MC, Kızılkan YE, Tavukçu HH, Yılmaz Ö. Comparison of Hounsfield Unit and Ontraoperative "GATA Scale" Score to Determine Requirement of DJ Stent Insertion in Ureteral Stone Treatment. J Urol Surg 2020;7(1):27-32

๑Copyright 2020 by the Association of Urological Surgery / Journal of Urological Surgery published by Galenos Publishing House. 
lazer süresi, tamamlanan lazer litotripsinin toplam enerjisi ve GATA skala skoru için alıcı işletim karakteristiği analizi yapıldı ve optimal eşik sırasıyla $164,01 \mathrm{~mm}^{3}, 4,25$ dakika, $1004 \mathrm{~W}$ ve 7,5 saptandı.

Sonuç: Klinik pratikte, GATA skalası, DJ stentlerin yerleştirme kararında kullanılabilir. Özellikle taşın hacmi 160 mm $^{3}$ 'ün üzerinde veya toplam enerji 1000 W'nun üzerinde veya lazer süresi 4 dakikadan fazla veya GATA skalası 7'den fazla ise, litotripsiden sonra stent yerleştirilmesi önerilir.

Anahtar Kelimeler: Üreteral taş, Hounsfield ünitesi, Lazer litotripsi

\section{Introduction}

Urinary system stones have an important place in urology practice. The prevalence of urolithiasis in economically developed countries has been reported to range between $4 \%$ and 20\% (1). Large stones may cause obstruction and small ones may produce severe flank or lower abdominal pain. Location of pain varies with the location of the stone. Standard evaluation includes a detailed medical history and physical examination. In the evaluation of acute flank pain, non-contrast-enhanced computed tomography (NCCT), which can determine stone density and plays a role in deciding the modality of treatment is the gold standard $(2,3)$. However, risks associated with radiation due to computed tomography (CT) scanning causes anxiety in everyone. Thus, low-dose and ultra-low-dose protocols are preferred. However, it should be noted that the diagnostic accuracy decreases as the dose decreases (4). Accuracy of hounsfield units (HU) may be queried considering all the above concerns.

In this study, we aimed to determine the contribution of HU measurement to choosing the correct treatment option for a single ureteral stone, and to demonstrate the accuracy or fallibility. Also, we planned to investigate the right alternatives that can be used instead of $\mathrm{HU}$ and contribute to clinical practice.

\section{Materials and Methods}

\section{Patient Population}

A total of 90 patients, 77 males and 13 females, who underwent holmium laser lithotripsy (LL) using semirigid ureteroscope for the treatment of single ureteral stone in our clinic between January 2018 and September 2018 were prospectively reviewed.

\section{Inclusion and Exclusion Criteria}

Patients aged 18 years and older having a single ureteral stone were enrolled in the study. Patients, who were found to have missing data during data recording, evaluation or analysis, were excluded from the study. Patients under the age of 18, patients with surgical failure and patients who received combined therapy (LL and pneumatic lithotripsy) were not included in the study.

\section{Study Design}

The study was designed as a prospective study and was conducted according to the principles of the Declaration of Helsinki. No additional test or assessment other than the evaluations performed for the diagnosis of ureteral stone in routine urology practice was done (physical examination, radiography and NCCT).

Age, gender, presence and location of pain, presence of additional disease, history of previous shock-wave lithotripsy or surgery for urolithiasis, smoking habit, stone location, stone volume, opacity of stone, degree of hydronephrosis, presence of ureteral stenosis or ureteral orifice stenosis and presence or absence of ureteral stent placement were recorded.

All patients were evaluated with NCCT preoperatively. Stone protocol NCCT was performed using a 64 detector row helical CT scanner at $120 \mathrm{kV}, 240 \mathrm{~mA}$, with $1.25 \mathrm{~mm}$ collimation. Stone location was recorded for each patient. Stone location was classified as proximal ureteral, mid ureteral and intramural ureteral. Stone volume was calculated by measuring the three dimensions of the stone in millimeters and then using the formula: length $\times$ width $\times$ height $\times \pi \times 1 / 6(5,6)$. $\mathrm{HU}$ calculations were performed for each stone in 3 different areas on CT images and the mean value was taken.

\section{Surgical Procedure}

Ureteroscopy (URS) with holmium LL (URS-LL) was performed by four urologists (minimum 5 years of experience in the field). We used semirigid ureteroscope $27000 \mathrm{~L} / \mathrm{K}$ or $27001 \mathrm{~L} / \mathrm{K}$ (diameter proximal and distal, 7/6.5 and 8/7 $\mathrm{Fr}$, respectively) models of Storz (Germany) and Holmium-YAG laser by the Sphinx 80 Litho (Power Suite 80 W, Katlenburg-Lindau, Germany) for lithotripsy. Excitation/emission wavelengths of the laser fiber were 230/365 $\mu \mathrm{m}$ with an output energy of $0.5 / 4.5 \mathrm{~J}$ and a pulse repetition rate of $4 / 30 \mathrm{~Hz}$. In URS, the calculi were targeted; dusting was preferred as the main option or the stones were fragmented into pieces as small as possible and stones $>4 \mathrm{~mm}$ were removed with a basket catheter. Smaller fragments were expected to pass spontaneously. The efficacy of lithotripsy was evaluated by ultrasound and abdominal $\mathrm{X}$-ray one day later.

\section{A New "GATA" Scale}

To compare HU to intraoperative findings; stone hardness, intraoperative laser duration and the total energy to complete 
LL were intraoperatively recorded. We designed a questionnaire for the surgeons to fill immediately after each URS. Then, all the patients were divided into three groups according to results for the balanced distribution of the patients in all groups. There were 29, 30 and 31 patients in group 1, 2 and 3, respectively (according to stone hardness, intraoperative laser duration and the total energy to complete $\mathrm{LL}$ ). Three main subjects were scored from 1 to 3 in the questionnaire. Stone hardness was scored from 1 to 3 (soft, medium-hard and hard). Laser duration that is defined as the time between beginning and end of lithotripsy was calculated and scored from 1 to 3 (0-3.99 $\mathrm{min}, 4-7.99 \mathrm{~min}$ and $>8 \mathrm{~min}$ ). The total energy to complete $\mathrm{LL}$ for each stone was calculated by multiplying pulse energy $(\mathrm{J})$ by frequency $(\mathrm{Hz})$ and scored from 1 to 3 (0-999 W, 1000-2499 W and >2500 W). Total score of the scale was between 3 and 9 point. HU and GATA scale score were compared statistically to find the accuracy of $\mathrm{HU}$.

\section{Statistical Analysis}

Statistical analyses were performed using SPSS Statistics 22.0 software (SPSS Inc., Chicago, IL, USA) and Microsoft Excel computer programs. The normality hypothesis was tested using the Kolmogorov-Smirnov test during data analysis. Descriptive statistics for continuous variables were presented as mean and standard deviation. Pearson's correlation coefficient and Spearman's correlation coefficient were used for correlation analyses of the parameters. Also, multinomial logistic regression was evaluated to determine the significance of the risk/effect parameters. Receiver operating characteristic (ROC) curve was applied to determine the cut-off value for significant parameters. Statistical significance was defined as $p<0.05$.

\section{Results}

The mean age of the patients was $45.8 \pm 1.52$ years (range, 21 75 years). Regarding primary presenting complaints, flank pain was present in 95.55\% (86/90). Left flank pain was observed in $51.11 \%$ of cases. $24.44 \%$ (22/90) of patients had a history of surgical procedure for urinary calculi, and $72.72 \%$ (16/22) underwent lithotripsy. 30\% (27/90) of patients had a history of shock-wave lithotripsy. Additional disease was found in $28.88 \%$ (26/90) of patients. Diabetes Mellitus, hypertension and coronary artery disease were detected in 4,12 and 4 patients, respectively. 6 of 26 patients had a combination of these diseases. 22.22\% (20/90) of patients was smoker or tobacco user.

The location of the stone was proximal ureter, mid ureter and intramural ureter in 37.77\% (34/90), 41.11\% (37/90) and 21.11 (19/90) of patients, respectively. The mean stone volume at diagnosis in patients with ureteral calculi was $245.29 \pm 23.9$ $\mathrm{mm}^{3}$. Hydronephrosis was found in $91.11 \%(82 / 90)$ of patients with ureteral calculi and the degree of hydronephrosis was grade 1 in 26.82\%, 2 in 39.02\%, 3 in 32.92\% and grade 4 in $1.21 \%$ of patients. The mean HU was $1065.21 \pm 33.5$ (Table 1). $74.44 \%$ (67/90) of patients had opaque, 21.11\% (19/90) had semi-opaque and 4.44\% (4/90) had non-opaque stones.

The mean GATA scale score was $6.44 \pm 0.2$. 17.77\% (16/90) of patients had soft, 27.77\% (25/90) had medium-hard and 54.44\% (49/90) had hard stones. The mean laser duration was $8.18 \pm 0.89$ $\min$. The mean total energy to complete LL was $3258.18 \pm 630 \mathrm{~W}$ (Table 1).

Stent placement after URS-LL was performed in 66.66\% (60/90). In 30 patients, stent placement was not required. The GATA scale score was statistically significantly higher in patients who required DJ stent placement $(p<0.0001)$. All patients were successfully treated.

There was a statistically significant positive correlation between $\mathrm{HU}$ and total GATA scale score. The Spearman's correlation coefficient was 0.49 for this result. There was a statistically significant positive correlation between stone size and $\mathrm{HU}$ $(p<0.05)$. Also, there was a statistically significant positive correlation between opacity of stones and HU or GATA scale score $(p<0.05)$. There was no statistically significant correlation between the size of ureteral stenosis or ureteral orifice stenosis and HU or GATA scale score.

To determine the threshold value for factors affecting stent placement after lithotripsy, ROC analysis performed for stone volume, laser duration, total energy to complete LL and GATA scale score showed that the optimal threshold values were $164.01 \mathrm{~mm}^{3}$ (sensitivity: 60\%; specificity: 70\%), 4.25 mins (sensitivity: 68\%; specificity: 73\%) 1004 W (sensitivity: 80\%; specificity: 60\%) and 7.5 (sensitivity: 45\%; specificity: 90\%), respectively. $\left(A \cup C_{\text {stone volume }}=0.70, A U C_{\text {laser duration }}=0.73, A U C_{\text {laser }}\right.$ energy $=0.75$ and $\mathrm{AUC}_{\text {GATA scale score }}=0.71$ ) (Table 2 and 3 ) (Figure 1).

\section{Discussion}

Especially in Western countries, urinary stones are one of the most common urological diseases (7). Diagnosis of ureteral stones is rapid using low-dose CT (8). The EAU 2018 urolithiasis

Table 1. Evaluation of descriptive characteristics in patients with ureteral stone were managed by URS-LL

\begin{tabular}{|l|l|}
\hline Variable & Mean \pm standart deviation $(\mathbf{n = 9 0})$ \\
\hline Age (years) & $45.8 \pm 1.52$ \\
\hline Volume of stone $\left(\mathrm{mm}^{3}\right)$ & $245.29 \pm 23.9$ \\
\hline Hounsfiel unit $(\mathrm{HU})$ & $1065.21 \pm 33.5$ \\
\hline Laser duration $(\mathrm{min})$ & $8.18 \pm 0.89$ \\
\hline Laser energy $(\mathrm{W})$ & $3258.18 \pm 630$ \\
\hline GATA scale score & $6.44 \pm 0.2$ \\
\hline
\end{tabular}


Table 2. Area under the curve of stone volume, laser duration, laser energy and GATA scale score. Evulation of success in these parameters to predict of stent placement

\begin{tabular}{|c|c|c|c|c|c|}
\hline \multirow{2}{*}{ Test result variable (s) } & \multirow{2}{*}{ Area } & \multirow{2}{*}{$\begin{array}{l}\text { Standard } \\
\text { error }^{\mathrm{a}}\end{array}$} & \multirow{2}{*}{ Asymptotic sig. ${ }^{b}$} & \multicolumn{2}{|c|}{ Asymptotic $95 \%$ confidence interva } \\
\hline & & & & Lower bound & Upper bound \\
\hline Stone volume & 0.707 & 0.057 & 0.001 & 0.595 & 0.819 \\
\hline Laser energy & 0.754 & 0.055 & 0.000 & 0.646 & 0.861 \\
\hline GATA scale score & 0.718 & 0.057 & 0.001 & 0.607 & 0.830 \\
\hline
\end{tabular}

Table 3. Receiver operating characteristic curve of stone volume, laser duration, laser energy and GATA scale score and sensitivity and specificity ratios of threshold values

\begin{tabular}{|l|l|l|l|l|l|}
\hline Variable & Cut-off value & Sensivity & Specificity & LR+ & LR- \\
\hline Stone volume & $164.01 \mathrm{~mm} 3$ & 60 & 70 & 2 & 0.57 \\
\hline Laser duration & $4.25 \mathrm{mins}$ & 68.3 & 73.3 & 2.55 & 0.44 \\
\hline Laser energy & $1004 \mathrm{~W}$ & 80 & 60 & 2 & 0.33 \\
\hline GATA scale score & 7.5 & 45 & 90 & 4.5 & 0.61 \\
\hline LR: Likelihood ratio & \multicolumn{5}{|l}{} \\
\hline
\end{tabular}

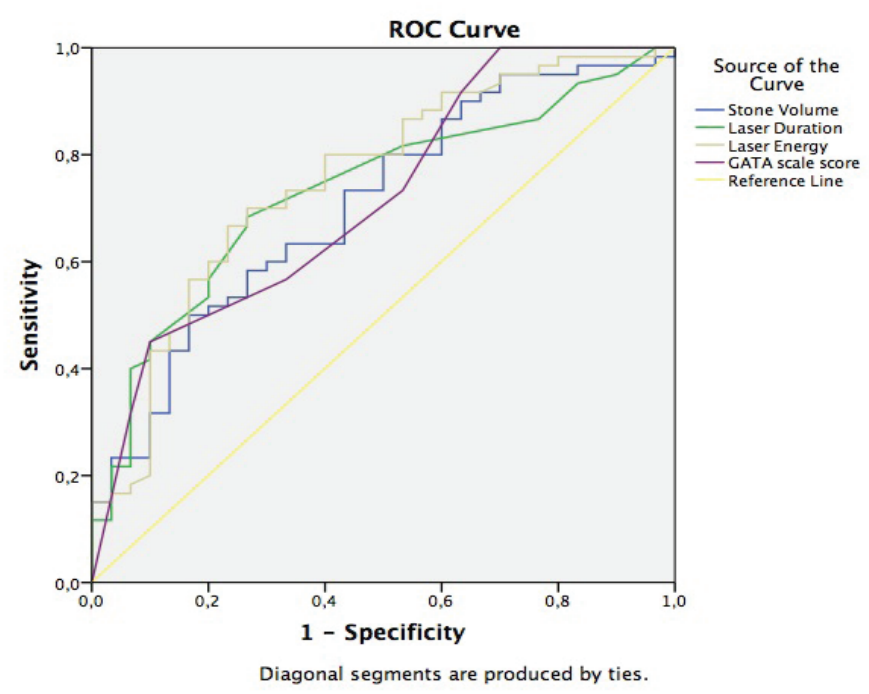

Figure 1. Diagonal segments are produced by ties

ROC: Receiver operating characteristic

guideline strongly recommends evaluation of HU on NCCT for ureteral stones (9). HU can be used for diagnosis and selection of the treatment options. However, these methods do not predict the composition of stones with high accuracy.

$\mathrm{HU}, \mathrm{HU}$ density or $\mathrm{HU}_{\text {diff }}$ can be used for assessment of ureteral stones (10). These parameters have been evaluated in the literature and their success has been proven in many studies with different results. Baran et al. (11) and Deshmukh and et al. (12) reported that kidneys in patients with calculi have a comparatively high renal cortex and papillae densities than in normal population. However, when the articles were examined in detail, there was no statistically significant difference between some poles of the kidney. These findings support some concerns such as heterogeneity of the measuring area or variability of $\mathrm{HU}$ values. In the literature, there are a lot of studies for estimating stone composition with $\mathrm{HU}$ values. In some studies, it was reported that HU on NCCT could differentiate just calcium from non-calcium stones $(13,14,15)$. Patel et al. $(16)$ found that HU measurement of urinary stones on NCCT may be used for differentiation of various calcium stone subtypes. However, Stewart et al. (17) reported that for calcium stones, the ability of $\mathrm{HU}$ on NCCT to predict stone composition was limited. For brushite stones, $\mathrm{HU}$ and $\mathrm{HU}$ density can help predict stone composition (18). In another study, Motley et al. (19) reported that neither HU density nor mean $\mathrm{HU}$ value was able to identify urinary stones in vivo and to evaluate radiodensities of ureteral stones; HU density was better than $\mathrm{HU}$ value. These results show that the $\mathrm{HU}$ value changes due to differences in stone composition. However, HU measurements are affected by the heterogeneity of the stone as well as the metabolic structure of the stone. In our study, 49\% correlation which was found in our cohort contributes to the debate on the reliability of this method. Deciding by HU value when evaluating treatment options leads to a wrong decision in approximately $50 \%$ of cases.

$\mathrm{HU}$ can be used in choosing among treatment options ( $S W L$, URS-LL or percutaneous antegrade removal) for ureteral stones. Ouzaid et al. (20) reported that HU was a prognostic factor for success of extracorporeal shockwave lithotripsy (SWL) and 970 HU represented the most sensitive (100\%) and specific (81\%) point on the ROC curve. Thus, urinary stones with a mean stone density of $>1000 \mathrm{HU}$ is deemed to be resistant to SWL (21). ElAssmy et al. (22) found that a stone attenuation of $\leq 600 \mathrm{HU}$ was 
a significant independent predictor of SWL success in children. However, $\mathrm{HU}$ does not seem to be a predictive parameter for stone expulsion (23). In our cohort, the mean HU value was 1065.21. In our study, there was no correlation between HU value and GATA scale score in patients with a high HU value. Therefore, HU evaluation led us to perform URS-LL in some patients instead of SWL and SWL instead of URS-LL in some patients, which resulted in treatment failure. Also SWL is not a cost-effective treatment option (24). For this reason, a wrong treatment choice leads to a high cost.

In the treatment, rigid or flexible ureterorenoscopes can be used (25). URS-LL has high stone-free rates in all locations of the urinary tract and with all stone types and sizes (26). In URS$\mathrm{LL}$, fragmentation may be more advantageous than dusting for complete initial stone clearance (27). In our cases, URS-LL was usually performed for fragmentation and the success rate was $100 \%$ for ureteral stones. However, dusting method may be preferred especially for stones in the upper urinary tract. However, we did not need it because we routinely used stone cone in our cases.

Routine stenting is not necessary before URS or after uncomplicated URS (complete stone removal). In addition to stone removal, minimal damage to the ureter, such as edema, by using laser energy or URS during operation can lead to severe pain in the postoperative period. Therefore, stone removal is not the only criterion for stenting. However, intraoperative criteria for stent placement are not objective. A scoring based on laser energy, duration of the procedure or intraoperative evaluation has not been done before. Therefore, we think that cutoff values used in our study are extremely important. In addition, ureteral catheters may be routinely used for the first 24 hours after the operation in patients without stent placement. We apply this protocol in our patients. Especially in cases with high energy and long operative time, removal of the ureteral catheter can be waited for up to 48 hours after the operation.

\section{Study Limitations}

The present study has several limitations. This is a single-center study with a small sample size. In our cases, we do not routinely use metabolic evaluation for ureteral stone patients after surgery and accept the fact that not all patients were operated on by a single surgeon experienced in the field of endourology. For these reasons, we believe that larger case series will be more effective in the interpretation of these findings, especially in the evaluation of GATA scale score.

\section{Conclusion}

$\mathrm{HU}$ is used for decision of treatment modality in patients with ureteral stones. But we found that HU had a weak correlation with intraoperative GATA scale score. Thus, HU led to false choice in approximately half of the patients. Also GATA scale score can be use in decision making for DJ stent placement. Especially if the volume of the stone is over $160 \mathrm{~mm}^{3}$ or the total energy is over $1000 \mathrm{~W}$ or the laser duration is more than 4 minutes or GATA scale score more than 7, stent placement after lithotripsy is recommended.

\section{Acknowledgments}

The authors would like to thank the entire staff of the Sultan Abdulhamid Han Training and Research Hospital, Clinic of Urology.

\section{Ethics}

Ethics Committee Approval: Institutional review board (IRB) approval was acquired from our clinic committee.

Informed Consent: Informed consent was obtained from all individual participants included in the study.

Peer-review: Externally and internally peer-reviewed.

\section{Authorship Contributions}

Concept: C.E., Ö.Y., Design: C.E., Data Collection or Processing: C.E., Y.E.K., S.A., S.E.Ş., Analysis or Interpretation: C.E., Ö.Y., M.C.T., Literature Search: C.E., H.H.T., Writing: C.E., Ö.Y.

Conflict of Interest: No conflict of interest was declared by the authors.

Financial Disclosure: The authors declare that they have no relevant financial.

\section{References}

1. Trinchieri A. Epidemiology of urolithiasis: an update. Clin Cases Miner Bone Metab 2008;5:101-106.

2. Worster A, Preyra I, Weaver B, Haines T. The accuracy of noncontrast helical computed tomography versus intravenous pyelography in the diagnosis of suspected acute urolithiasis: a meta-analysis. Ann Emerg Med 2002;40:280286.

3. Zarse CA, Hameed TA, Jackson ME, Pishchalnikov YA, Lingeman JE, McAteer $J A$, Williams JC, Jr. CT visible internal stone structure, but not Hounsfield unit value, of calcium oxalate monohydrate (COM) calculi predicts lithotripsy fragility in vitro. Urol Res 2007;35:201-206.

4. Smith-Bindman R, Moghadassi M, Griffey RT, Camargo CA, Jr., Bailitz J, Beland M, Miglioretti DL. Computed Tomography Radiation Dose in Patients With Suspected Urolithiasis. JAMA Intern Med 2015;175:1413-1416.

5. Ito $H$, Kawahara $T$, Terao $H$, Ogawa $T$, Yao $M$, Kubota $Y$, Matsuzaki J. Predictive value of attenuation coefficients measured as Hounsfield units on noncontrast computed tomography during flexible ureteroscopy with holmium laser lithotripsy: a single-center experience. J Endourol 2012;26:1125-1130

6. Ito H, Kawahara T, Terao H, Ogawa T, Yao M, Kubota Y, Matsuzaki J. The most reliable preoperative assessment of renal stone burden as a predictor of stone-free status after flexible ureteroscopy with holmium laser lithotripsy: a single-center experience. Urology 2012;80:524-528. 
7. Stolzmann $P$, Kozomara $M$, Chuck $N$, Muntener $M$, Leschka S, Scheffel $\mathrm{H}$, Alkadhi $\mathrm{H}$. In vivo identification of uric acid stones with dual-energy CT: diagnostic performance evaluation in patients. Abdom Imaging 2010;35:629-635

8. Turk C, Petrik A, Sarica K, Seitz C, Skolarikos A, Straub M, Knoll T. EAU Guidelines on Diagnosis and Conservative Management of Urolithiasis. Eur Urol 2016;69:468-474.

9. Türk C, Neisius A, Petřik A, Seitz C, Thomas K, Skolarikos A. EAU Guidelines on Urolithiasis 2018. European Association of Urology Guidelines. 2018 Edition., Vol presented at the EAU Annual Congress Copenhagen 2018. Arnhem, The Netherlands, The European Association of Urology Guidelines Office, 2018.

10. Celik S, Sefik E, Basmaci I, Bozkurt IH, Aydin ME, Yonguc T, Degirmenci T. A novel method for prediction of stone composition: the average and difference of Hounsfield units and their cut-off values. Int Urol Nephrol 2018;50:1397-1405.

11. Baran I, Voyvoda N, Tokgoz O, Tokgoz H. Can Hounsfield unit values of the cortex and papillae determined by computed tomography demonstrate the possibility of kidney stone formation? Eur J Radiol 2012;81:1446-1449.

12. Deshmukh S, Kambadakone A, Sahani DV, Eisner BH. Hounsfield density of renal papillae in stone formers: analysis based on stone composition. J Urol 2015;193:1560-1563.

13. Shahnani PS, Karami M, Astane B, Janghorbani M. The comparative survey of Hounsfield units of stone composition in urolithiasis patients. J Res Med Sci 2014;19:650-653.

14. Otsuki H, Yoshioka T, Shimizu T, Nakanishi Y, Fujio K, Murao W, Uehara S, Kikuchi H, Fujio K. Calcium Phosphate Composition Affects Ureteroscopic Laser Lithotripsy. Acta Med Okayama 2016;70:25-29.

15. Altan M, Citamak B, Bozaci AC, Gunes A, Dogan HS, Haliloglu M, Tekgul S. Predicting the stone composition of children preoperatively by Hounsfield unit detection on non-contrast computed tomography. J Pediatr Urol 2017;13:505 e501-505 e506.

16. Patel $S R$, Haleblian G, Zabbo A, Pareek G. Hounsfield units on computed tomography predict calcium stone subtype composition. Urol Int 2009;83:175-180

17. Stewart G, Johnson L, Ganesh H, Davenport D, Smelser W, Crispen P, Venkatesh R. Stone size limits the use of Hounsfield units for prediction of calcium oxalate stone composition. Urology 2015;85:292-295.

18. Tailly $T$, Larish $Y$, Nadeau B, Violette $P$, Glickman L, Olvera-Posada D, Alenezi $\mathrm{H}$, Amann J, Denstedt J, Razvi H. Combining Mean and Standard Deviation of Hounsfield Unit Measurements from Preoperative CT Allows More Accurate Prediction of Urinary Stone Composition Than Mean Hounsfield Units Alone. J Endourol 2016;30:453-459.

19. Motley G, Dalrymple N, Keesling C, Fischer J, Harmon W. Hounsfield unit density in the determination of urinary stone composition. Urology 2001;58:170-173.

20. Ouzaid I, Al-qahtani S, Dominique S, Hupertan V, Fernandez P, Hermieu JF, Delmas V, Ravery V. A 970 Hounsfield units (HU) threshold of kidney stone density on non-contrast computed tomography (NCCT) improves patients' selection for extracorporeal shockwave lithotripsy (ESWL): evidence from a prospective study. BJU Int 2012;110:E438-442.

21. Lee JY, Kim JH, Kang DH, Chung DY, Lee DH, Do Jung H, Kwon JK, Cho KS Stone heterogeneity index as the standard deviation of Hounsfield units: A novel predictor for shock-wave lithotripsy outcomes in ureter calculi. Sci Rep 2016;6:23988.

22. El-Assmy A, El-Nahas AR, Abou-El-Ghar ME, Awad BA, Sheir KZ. Kidney stone size and hounsfield units predict successful shockwave lithotripsy in children. Urology 2013;81:880-884.

23. Balci M, Tuncel A, Aydin O, Aslan Y, Guzel O, Toprak U, Polat F, Atan A. Tamsulosin versus nifedipin in medical expulsive therapy for distal ureteral stones and the predictive value of Hounsfield unit in stone expulsion. Ren Fail 2014;36:1541-1544.

24. Cone EB, Pareek G, Ursiny M, Eisner B. Cost-effectiveness comparison of ureteral calculi treated with ureteroscopic laser lithotripsy versus shockwave lithotripsy. World J Urol 2017;35:161-166.

25. Preminger GM, Tiselius HG, Assimos DG, Alken P, Buck AC, Gallucci M, Knoll T, Lingeman JE, Nakada SY, Pearle MS, Sarica K, Turk C, Wolf JS, Jr., American Urological Association E, Research I, European Association of U. 2007 Guideline for the management of ureteral calculi. Eur Urol 2007;52:16101631.

26. Santiago JE, Hollander AB, Soni SD, Link RE, Mayer WA. To Dust or Not To Dust: a Systematic Review of Ureteroscopic Laser Lithotripsy Techniques. Curr Urol Rep 2017;18:32.

27. Matlaga BR, Chew $B$, Eisner $B$, Humphreys $M$, Knudsen $B$, Krambeck $A$, Lange D, Lipkin M, Miller NL, Monga M, Pais V, Sur RL, Shah O. Ureteroscopic Laser Lithotripsy: A Review of Dusting vs Fragmentation with Extraction. J Endourol 2018;32:1-6. 